\title{
Optimum Operation of a PVDF-type Hollow Fiber Membrane Bioreactor for Continuous Sewage Treatment
}

\author{
Choon-Hwan Shin ${ }^{*}$ \\ Department of Energy \& Environmental Engineering, Dongseo University, Busan 607-716, Korea \\ (Manuscript received 7 September, 2010; revised 8 October, 2010; accepted 25 October, 2010)
}

\begin{abstract}
A membrane bioreactor (MBR) was designed using polyvinylidene fluoride(PVDF)-type hollow fiber membrane modules with a treatment capacity of 10 ton/day. A pilot plant was installed in a sewage treatment plant and was operated with an intermittent aeration method which avoids any concentration gradient of suspended solids (SS) in the MBR. For continuous operation, the pilot plant was first tested with influent (mixed liquor suspended solid:MLSS of 1000-2000 mg/L) of aeration tanks in the sewage treatment plant. The MBR was pre-treated with washing water, $10 \%$ ethanol solution, $5 \% \mathrm{NaOCl}$ solution and finally washing water, one after another. To demonstrate the effect of the MBR on sewage treatment, compared with conventional activated sludge processes, we investigated the relationships among permeate amount (LMH), change in operation conditions, influent MLSS level and sludge production. It was found that the optimum aeration rate and suction pressure were $0.3 \mathrm{~m}^{3} / \mathrm{min}$ and 30 31 cmHg, respectively. Under stable conditions in aeration, suction pressure, influent flow rate and drainage, the SS removal efficiency was more than $99.99 \%$ even when the MLSS loading rate changes. Compared with conventional activated sludge processes, the MBR was more effective in cost reduction by $27 \%$ based on permeate amount and by $51.5 \%$ on sludge production.
\end{abstract}

Key Words : MBR, PVDF hollow fiber, Cost reduction, Sewage treatment, SS removal, Optimum operation

\section{Introduction}

Synthetic membranes, since 1960s, have been used for solid/liquid separation. As the membrane technologies such as microfiltration (MF) and ultrafiltration (UF) membranes are developed, their applications have been broadened to ultrapure water production, medicine and antibiotic refinement, extending to municipal sewage and industrial wastewater treatment (Li, 2003; Melin et al., 2006; Yang et al., 2006; Jolivalt et al., 2000). Current membrane technologies also grow into, for instance, water treatment with

\footnotetext{
${ }^{*}$ Corresponding author : Choon-Hwan Shin, Department of Energy \& Environmental Engineering, Dongseo University, Busan 607-716, Korea

Phone: +82-51-320-1787

E-mail:6116shin@dongseo.ac.kr
}

nano materials (Chang and Judd, 2002; Herzberg and Elimelech, 2007; Ivnitski et al., 2005; Singh et al., 2005). In particular, as conventional activated sludge processes are energy-intensive, suffering from high operating costs and large site area, they have been required to cut down by engaging other alternative or advanced processes such as membrane separation processes with submerged membrane bioreactors (MBRs) and optimization of their operating conditions with various MLSS levels (Shin, 2009).

In membrane separation processes with MBRs, however, unavoidable concentration polarization yields an irreversible problem with membrane fouling, giving rise to poor membrane performance. Accordingly, various technologies to reduce membrane fouling have been suggested, including use of hydrophilic or hydrophobic membranes in 
response to treating water composition, recovery of surface pores with physical and chemical washing, suction pressure reduction with dispersively-arranged membrane modules, and use of functional membranes (Le-Clech et al., 2006; Yamamoto et al., 2006; Nakamura and Matzumoto, 2006). Amongst the technologies above, hollow fiber membranes are widely used because they possess larger surface area per volume, offering easier backwashing, compared with plate modules (high installation costs) and tubular modules (inconvenient membrane replacement) (Yamamori et al., 1996). In this respect, we designed a MBR with dispersively-arranged PVDF-type hollow fiber membranes which were surface-treated with $\mathrm{TiO}_{2}$. A pilot plant was installed and operated with an intermittent aeration method which can avoid any concentration gradient of suspended solids (SS) in the MBR. In this paper, the MBR performance was investigated in terms of permeate amount with backwashing, suction pressure change and SS removal efficiency. In addition, compared with conventional activated sludge processes, we investigated the relationships among permeate amount $(\mathrm{LMH})$, change in operation conditions, excess sludge production, effluent MLSS concentration and sludge production under conditions with the aeration rate and the suction pressure of $0.3 \mathrm{~m}^{3} / \mathrm{min}$ and $30 \sim 31 \mathrm{cmHg}$, respectively.

\section{Materials and methods}

\subsection{Membrane arrangement}

Our previous results(Shin and Johnson, 2007; Shin et al., 2009) suggest that the permeate flux can be maximized when 4 bundles of hollow fiber membranes were used and that lower packing density leads to lower pressure difference between membranes. Thus, these conditions were applied in this study. The permeate flux can be calculated by measuring the permeate amount per filtration time during suction operation as follows;

$$
\begin{aligned}
& \text { Permeate Flux }\left(\mathrm{L} / \mathrm{m}^{2} \cdot \mathrm{h}\right)=\mathrm{V} /(\mathrm{A} \cdot \mathrm{T}) \\
& \text { where } \mathrm{V}=\text { permeate amount }(\mathrm{L}) \\
& A=\text { membrane surface area }\left(\mathrm{m}^{2}\right) \\
& \mathrm{T}=\text { filtration time }(\mathrm{h})
\end{aligned}
$$

\subsection{Membrane module configuration}

The membrane module for MBR design consisted of $\mathrm{TiO}_{2}$ surface-treated PVDF-type hollow fiber (which was obtained from a domestic $\mathrm{W}$ company) and was dispersively arranged with 4 bundles, keeping the total membrane area of about $20 \mathrm{~m}^{2}$ (Shin, 2009; Shin and Johnson, 2007). The membrane configuration is detailed in Table 1.

Table 1. Configuration of membrane module

\begin{tabular}{cc}
\hline Properties & Conditions \\
\hline Module type & Top Head \\
\hline Module dimension & $900(\mathrm{H}) \times 75(\mathrm{~W}) \times 580(\mathrm{~L}) \mathrm{mm}$ \\
\hline Module material & $\mathrm{ABS}$ \\
\hline Net weight & $6 \mathrm{Kg}$ \\
\hline Adhesive & Poly-urethane/Epoxy resin \\
\hline Membrane type & Hollow fiber \\
\hline Surface area & $20 \mathrm{~m}^{2}$ \\
\hline Pore size & $0.1 \mu \mathrm{m}$ \\
\hline Porosity & $45 \%$ \\
\hline Hollow fiber looseness & $<0.5 \%$ \\
\hline Flux & $460 \mathrm{LMH}$ with drinking water \\
\hline at $25^{\circ} \mathrm{C}$ \\
\hline Mombrane material & PVDF (Polyvinylidene \\
\hline Characteristics & fluoride) \\
\hline Hollow fiber outer diameter & Hydrophilic \\
\hline fiber inner diameter & 2 mm \\
\hline Hiber tensile strength & 0.5 mm \\
\hline
\end{tabular}

\subsection{Module manufacture}

A membrane module with 4 bundles was installed to reduce the pressure difference between membranes and to secure a sufficient amount of permeate (Shin, 
2009). Fig. 1 illustrates the module (a) which was submerged in the MBR and the pilot plant (b) placed next to an aeration tank of a sewage treatment plant.

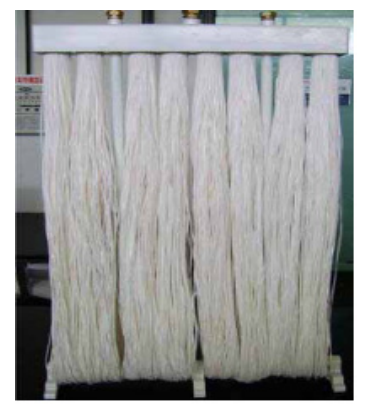

(a) Module

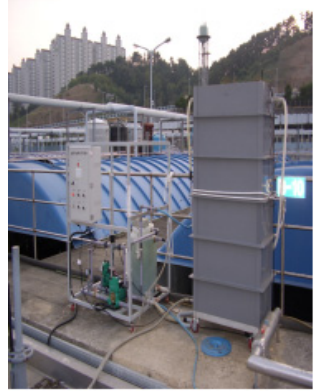

(b) Pilot plant
Fig. 1. MBR module and Pilot plant located in a sewage treatment plant.

\subsection{Operating conditions}

The MBR was pre-treated with washing water twice, $10 \%$ ethanol solution, $5 \% \mathrm{NaOCl}$ solution and finally washing water, one after another. For continuous operation, the pilot plant was first tested with raw water from an aeration tank of the sewage treatment plant. The MLSS level of the raw water ranged from 1000 to $2000 \mathrm{mg} / \mathrm{L}$. After backwashing the MBR, the correlation between operating factors such as the permeate amount and the suction pressure was investigated. The MLSS level and the sludge production were monitored during the continuous operation of the MBR. The operating conditions are summarized in Table 2.

Table 2. Conditions for continuous operation of the MBR

\begin{tabular}{cc}
\hline Condition & Range \\
\hline \hline Product to filtered & $1,000 \sim 15,000 \mathrm{mg} / \mathrm{L}$ (MLSS) \\
\hline Temperature & $0 \sim 60^{\circ} \mathrm{C}$ normal, 80 max \\
\hline Pressure & $0.1 \sim 1.0 \mathrm{~kg}_{\mathrm{f}} / \mathrm{cm}^{\circ}$ \\
\hline $\mathrm{pH}$ & $2 \sim 12$ \\
\hline Operating cycle & Suction $\Leftrightarrow$ Idle $\Leftrightarrow$ Backwashing \\
& $($ Air or water) \\
\hline Backwashing pressure & $0.5 \sim 1.0 \mathrm{~kg} / \mathrm{cm}^{\circ}$ \\
\hline Chemicals used & $\mathrm{H}_{2} \mathrm{O}_{2} / \mathrm{NaOCl}$ \\
\hline
\end{tabular}

\subsection{Optimum MLSS level for continuous operation} of the MBR

Five of batch-type activated sludge reactors were installed and operated with different MLSS levels. Each reactor was fed with $1 \mathrm{~L}$ of synthetic wastewater whose COD level was $680 \mathrm{mg} / \mathrm{L}$.

Table 3. Composition of synthetic wastewater

\begin{tabular}{cc}
\hline Chemicals & Concentration $(\mathrm{g} / \mathrm{L})$ \\
\hline \hline Glucose $\left(\mathrm{C}_{6} \mathrm{H}_{12} \mathrm{O}_{6}\right)$ & 1.000 \\
$\mathrm{KH}_{2} \mathrm{PO}_{4}$ & 0.533 \\
$\mathrm{~K}_{2} \mathrm{HPO}_{4}$ & 0.640 \\
$\left(\mathrm{NH}_{4}\right)_{2} \mathrm{SO}_{4}$ & 0.284 \\
$\mathrm{NH}_{4} \mathrm{Cl}$ & 0.427 \\
$\mathrm{CaCl}_{2} 2 \mathrm{H}_{2} \mathrm{O}$ & 0.013 \\
$\mathrm{MgSO}_{4} 7 \mathrm{H}_{2} \mathrm{O}$ & 0.178 \\
$\mathrm{MnSO}_{4} \mathrm{H}_{2} \mathrm{O}$ & 0.018 \\
$\mathrm{KCl}$ & 0.025 \\
$\mathrm{FeSO}_{4} 7 \mathrm{H}_{2} \mathrm{O}$ & 0.008 \\
\hline
\end{tabular}

The COD level in the reactor was measured to calculate the yield coefficient $(\mathrm{Y})$ and the endogenous respiration coefficient $\left(\mathrm{k}_{\mathrm{d}}\right)$ from the relationship between microorganisms and COD (Yamamoto et al., 2006). The experimental method is the same that of previous paper(Shin, 2009)

\subsection{Identification of microorganisms in the MBR}

During the continuous operation of the pilot plant, microorganisms present in the MBR were sampled regularly and identified with a polarization microscope (panasonic WV-700 Seiwa Optical, Japan).

\subsection{Estimation of operating cost}

The operating cost for the MBR system was estimated with a treatment capacity of $1,000 \mathrm{~m}^{3} / \mathrm{d}$ and with membranes having $3,183 \mathrm{~m}$ in length, $20 \mathrm{~m}^{2}$ in area and 4 modules. According to Busan Environmental Cooperation (Shin, 2008), the operating cost of the final clarifier was calculated by considering the permeate amount and the sludge production from the 
MBR system. Comparison with conventional activated sludge processes was made with the same treatment capacity. As the prices of the membrane, chemical agents and electricity are subject to change over time, it is noted in this paper that the cost comparison with conventional activated sludge processes is only based on current prices.

\section{Results and discussion}

\subsection{Microbial growth in the MBR}

Dominant microbial species in the MBR were identified to confirm that the continuous operation of the MBR was stable with various sludge retention time (SRT). That is, the influent quality of the MBR was the same as that of the aeration tanks whereas dominant microbial species can be different from each other, depending on SRT and concentration gradient (Visvanathan et al., 2003). In this study, the MLSS levels were found to be about $1,300 \mathrm{mg} / \mathrm{L}$ in the aeration tank and $1,800-2,000 \mathrm{mg} / \mathrm{L}$ in the MBR with various retention time, indicating that microbial species transferred from the aeration tank to the MBR increased the MLSS level due to microbial growth, which again depends on SRT. As changes in the MLSS level of the MBR are closely associated with dominant microbial species, they may be predicted by identifying the dominant microbial species in the MBR. Therefore, we endeavored to find out the reasons for the MLSS level change by demonstrating the dominant microbial species in the MBR. In this study, the MLSS level in the MBR was kept from 2,200 to $5,100 \mathrm{mg} / \mathrm{L}$ by adjusting SRT.

Vorticella, which usually appears when activated sludge is in good conditions, was observed with MLSS level of 2,200 mg/L, as shown in Fig. 2. When the MLSS level increased to 2,800 mg/L, Colurella as well as Vorticella were identified, indicating that microbial species can be changed with MLSS level of the MBR. Fig. 3 demonstrates the change in microbial species with MLSS level.

In addition, since microorganisms such as Aeolesoma are known to appear when activated sludge is piled up, being in poor conditions, such a

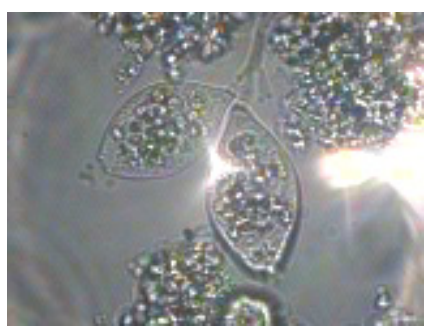

(a)

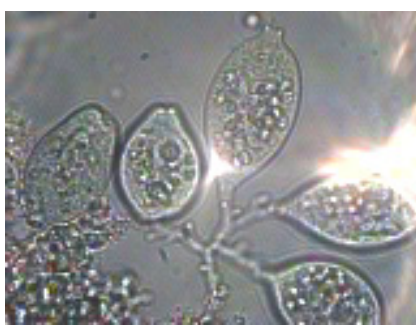

(b)

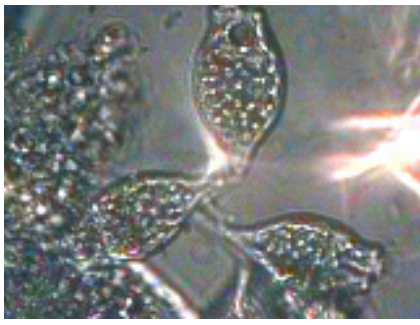

(c)

Fig. 2. Vorticella at MLSS level of 2,200 mg/L with SRT 0 (a), 3 days (b) and 9 days (c)(X 250).

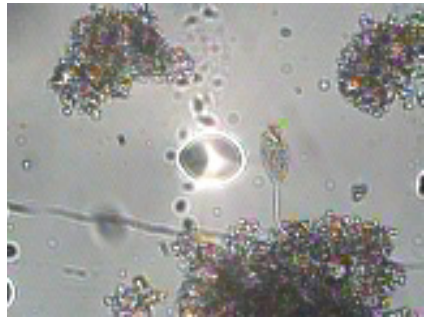

(a)

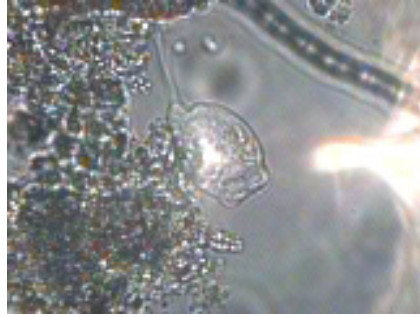

(b)

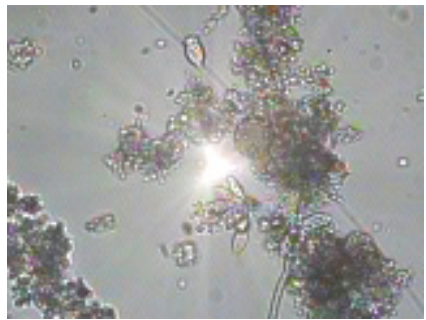

(c)

Fig. 3. Vorticella and Colurella at MLSS level of $2,800 \mathrm{mg} / \mathrm{L}$ with SRT 0(a), 3 days (b) and 9 days (c)(X 250). 
species was at times observed at MLSS level of about $1,700 \mathrm{mg} / \mathrm{L}$ in the MBR. This is possibly due to sludge accumulation inside the MBR. Therefore it is necessary to keep a certain level of MLSS in the MBR, implying that continuous removal of the accumulated sludge is required.

\subsection{Optimum MLSS level in the MBR}

The coefficients, $\mathrm{Y}$ and $\mathrm{k}_{\mathrm{d}}$, which are related to microbial metabolism relationship between $\Delta \mathrm{S} / \mathrm{X}_{\mathrm{AVG}}$ and $\Delta \mathrm{X} / \mathrm{X}_{\mathrm{AVG}}$. were found to be 0.7176 and 0.0296 day $^{-1}$, respectively. $350-600 \mathrm{mgCOD} / \mathrm{L}$. day was found to be the most effective with MLSS levels of $1,200-6,800 \mathrm{mg} / \mathrm{L}$. This result indicates that as long as the membranes are timely replaced, a long-term operation of the submerged MBR is feasible without producing excess sludge. (Shin, 2009)

\subsection{Sludge production with influent volumetric loading} rates

Fig. 4 which can be indicated the result of continuous operation with pilot plant located at aeration tank depicts the effect of the influent volumetric loading rate on the sludge production over operation time. The condition of continuous operation is the range of MLSS 1,900 2,200 mg/l, suction pressure 16 20 $\mathrm{CmHg}$, permeate $42 \sim 52 \mathrm{~L} / \mathrm{m}^{2}$.hr. The sludge production was calculated, based on the inflow quantity of the permeate reservoir (Shin, 2008). As can be seen in Fig. 4, the sludge production rate ranged from 165 to $218 \mathrm{~kg} /$ day with the influent MLSS level of 1,800 $\mathrm{mg} / \mathrm{L}$. The sludge production rate was found to vary while the influent volumetric loading rate (60 to 67.8 $\mathrm{L} / \mathrm{m}^{2} \mathrm{hr}$ ) was almost constant, as shown in Fig. 4. This is because an increase in SRT raised the MLSS level in the MBR, consequently increasing the sludge production. Thus, this result implies that polarization of MLSS level (which was due to extension of SRT) needs to be avoided by adjusting the drain valves at the bottom of the MBR. For the cost estimation of sludge production, the amount of drained sludge was kept constant at $60 \mathrm{~L} / \mathrm{m}^{2} \mathrm{hr}$, which led to a sludge production rate of $189 \mathrm{~kg} /$ day.

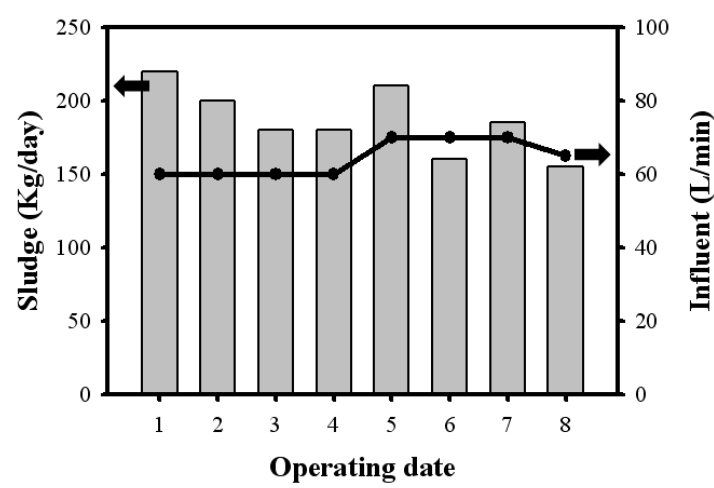

Fig. 4. Effect of influent volumetric loading rates on sludge production with MLSS level of $1,800 \mathrm{mg} / \mathrm{L}$ over operation time.

3.4. Effect of aeration rates on effluent MLSS level The effect of aeration rates on the effluent (permeate) MLSS level is illustrated in Fig. 5. The MBR was operated under conditions such as the influent rate of $62 \mathrm{~L} / \mathrm{m}^{2} \mathrm{hr}$, HRT $1 \mathrm{hr}$, suction pressure $31 \mathrm{cmHg}$ and influent MLSS level $1,900 \mathrm{mg} / \mathrm{L}$. It was found that more than $98.5 \%$ of MLSS was removed even without aeration. In this case, an appropriate aeration rate should be applied because fouling in the separation membranes (which are composed of modules) is expected to increase (Le-Clech et al., 2006).

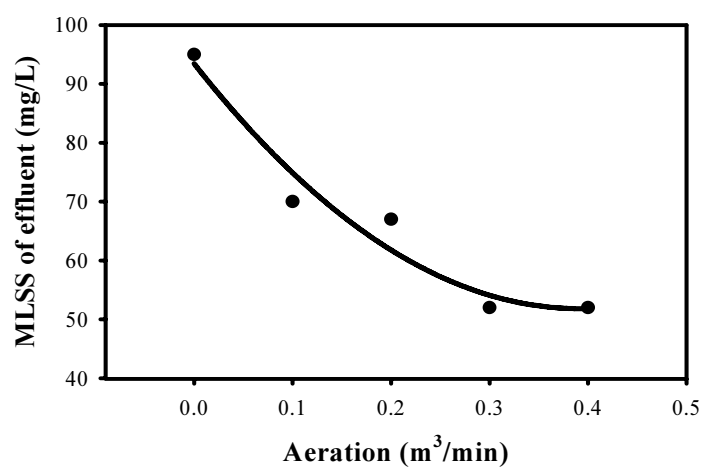

Fig. 5. Plot of effluent MLSS level against aeration rate. 
The results with aeration rates of $0.1-0.4 \mathrm{~m}^{3} / \mathrm{min}$ suggest that the MLSS removal efficiency increases with an increase in the aeration rate. As shown in Fig.5, the aeration rates of 0.3 and $0.4 \mathrm{~m}^{3} / \mathrm{min}$ resulted in the effluent MLSS levels of 53.3 and 50.9 $\mathrm{mg} / \mathrm{L}$, respectively, whose difference is virtually negligible. Therefore, it would be reasonable to set the aeration rate at $0.3 \mathrm{~m}^{3} / \mathrm{min}$.

\subsection{Suction pressure with aeration rates}

Fig. 6 depicts changes in suction pressure with aeration rates. As the aeraton rate increased, the suction pressure was found to decrease gradually from 41 (without aeration) to $31 \mathrm{cmHg}$ (with 0.4 $\mathrm{m}^{3} / \mathrm{min}$ ), which is consistent with the result from Ueda (1997). One would expect that no aeration would worsen membrane fouling. This is also consistent with the effect of aeration rates on MLSS level in the previous section. Thus, Fig. 6 confirms that the appropriate suction pressure may be $30 \sim 31 \mathrm{cmHg}$, which results in the aeration rate of $0.3 \mathrm{~m}^{3} / \mathrm{min}$.

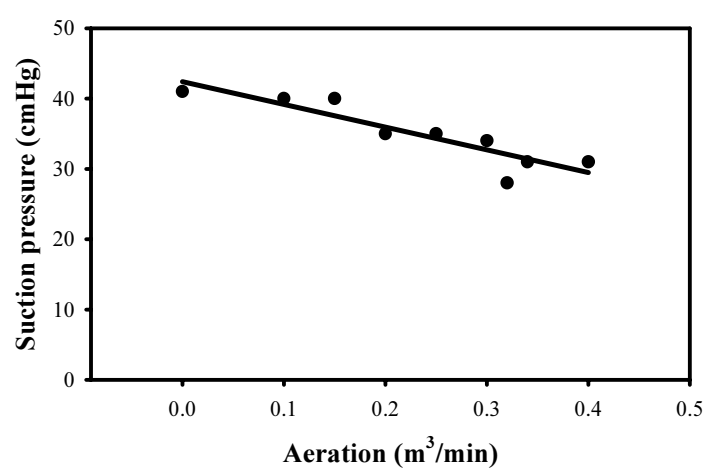

Fig. 6. Plot of suction pressure against aeration rates.

\subsection{SS removal efficiency}

Changes in MLSS level and its removal efficiency with operation time are shown in Fig.7. When the influent MLSS level ranges from 1,400 to 2,200 $\mathrm{mg} / \mathrm{L}$, the permeate MLSS level was found to be $0.2-0.4 \mathrm{mg} / \mathrm{L}$, resulting in the optimum filtration efficiency of more than $99.99 \%$. This confirms that the membrane used in this study yields excellent SS removal. Along with these conditions, the amount of permeate was used to estimate the operating costs in the later section. Supposing that the membrane breakthrough point takes place at $90 \%$ SS removal of the initial concentration, the pilot plant is currently running to investigate the possibility of continuous operation for more than 1000 days with MLSS level of $2,000 \mathrm{mg} / \mathrm{L}$.

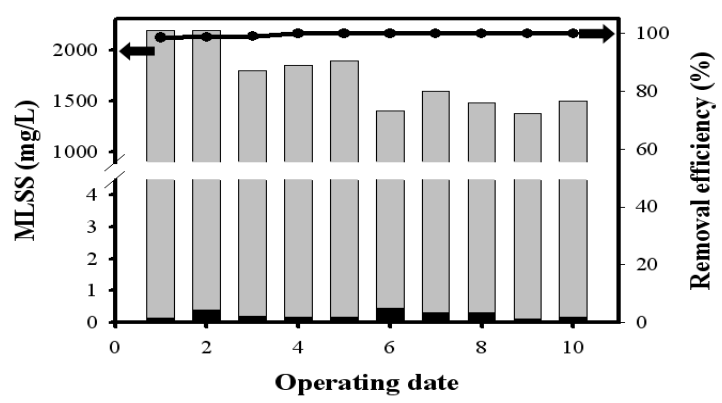

Fig. 7. SS removal efficiency with operation time.

\subsection{COD removal efficiency}

When the influent COD level was about 18.2 $35.0 \mathrm{mg} / \mathrm{L}$, the permeate COD level ranged from 11.3 to $21.0 \mathrm{mg} / \mathrm{L}$ as depicted in Fig. 8, resulting in the COD removal efficiency of $20.0 \sim 46.4 \%$. Although COD removal was not as satisfactory as SS removal, the former is an accompanying effect of the latter,

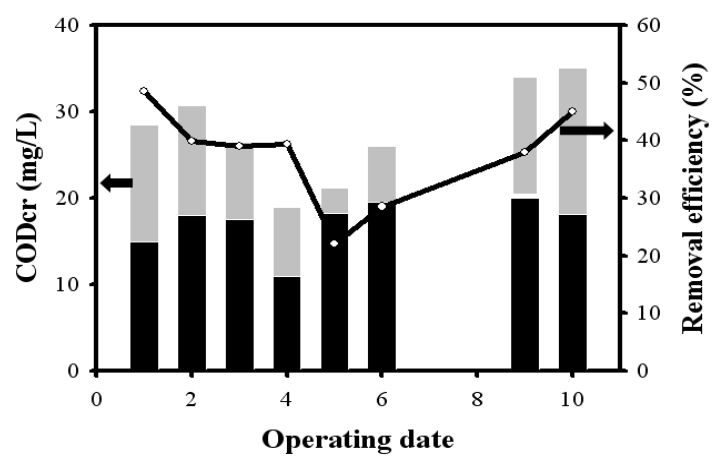

Fig. 8. $\mathrm{COD}_{\mathrm{Cr}}$ removal efficiency with operating date. 
considering that the latter is the main purpose of this study. Also, the influent (used in this study) of aeration thanks in the sewage treatment plant contained $94 \%$ of MLVSS, which is considered to be relatively high. As the separation membrane has an asymmetric character, COD removal is expected to be less effective than SS removal in the MBR.

\subsection{Comparison of operating costs}

The same initial investment cost was applied for the MBR and the conventional activated sludge processes to estimate their operating costs. Based on a treatment capacity of $1,000 \mathrm{~m}^{3} / \mathrm{d}$, it was calculated that the MBR required membranes with $3,183 \mathrm{~m}$ in length, $20 \mathrm{~m}^{2}$ in area and 4 modules. Based on the permeate amount and the sludge production, the operating costs were estimated with above conditions, as shown in Fig. 9. For the permeate amount basis, the operating costs for the MBR and the conventional processes were found to be 215 and $305 \mathrm{won} / \mathrm{m}^{3}$, respectively, resulting in about $27 \%$ cost reduction with the MBR. Base on sludge production, the MBR reduced the operating cost up to about $51.5 \%$, compared with the conventional processes. It is noted that the cost comparison with conventional activated sludge processes is only based on current prices which can be changed over time.

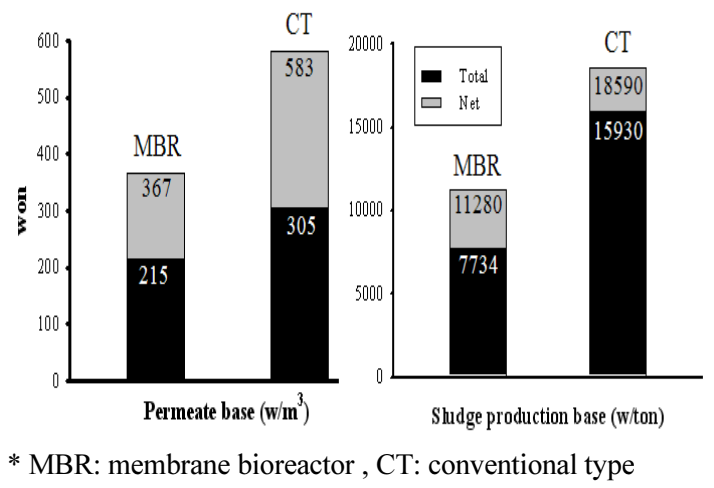

Fig. 9. Estimation of operating costs for MBR and CT.

\section{Conclusions}

A MBR using PVDF-type hollow fiber membranes was installed at Suyoung sewage treatment plant affiliated with Busan Environmental Corporation. Its continuous operation led to the following results.

1) With an aeration rate of $0.3 \mathrm{~m}^{3} / \mathrm{min}$, suction pressure 30-31 cmHg and influent MLSS level 1,400 - 2,200 $\mathrm{mg} / \mathrm{L}$, the continuous operation of the MBR yielded the SS removal efficiency of $99.99 \%$ and the permeate amount of $42-52 \mathrm{~L} / \mathrm{m}^{2} \mathrm{hr}$.

2) As an accompanying effect of SS removal, the COD removal efficiency was $20-46.4 \%$, which is unsatisfactory but expected because of the relatively high influent MLVSS level (94\%) and the asymmetric character of the separation membrane.

3) A long-term continuous operation of the MBR was confirmed to be possibile with MLSS level of $1,200-6,600 \mathrm{mg} / \mathrm{L}$ and COD loading of $350-600$ $\mathrm{kg} / \mathrm{d}$.

4) With stable conditions of aeration, suction pressure, inflow rates and sludge drainage, the SS removal efficiency was more than $99.99 \%$ even in the case of various influent MLSS levels. The current pilot plant is running with an assumption that the membrane breakthrough point takes place at $90 \%$ of SS removal efficiency. The comparison with the current results will be made in near future.

5) Compared with conventional methods, the MBR used in this study reduced the costs by about $27 \%$ based on the permeate amount and about $51.5 \%$ on the sludge production, possibly resulting in more cost reduction if domestic membrane production is more active in near future.

\section{Acknowledgment}

This study was supported by the research fund of the Busan Environmental Corporation (BECO). A 
part of the technical report to BECO is included in this paper.

\section{References}

Chang, I. S., Judd, S., 2002, Air sparging of a submerged MBR for municipal wastewater treatment, Proc. Biochem., 37, 915-920.

Herzberg, M., Elimelech, M., 2007, Biofouling of reverse osmosis membranes: role of biofilm-enhanced osmotic pressure, J. Membr. Sci., 295, 11-20.

Ivnitsky, H., Katz, I., Minz, D., Shimoni, E., Chen, Y., Tarchitzky, J. R., Semiat, R., Dosoretz, C. G., 2005, Characterization of membrane biofouling in nanofiltration processes of wastewater treatment, Desalination, 185, 255-268.

Jolivalt, C., Brenon, S., Caminade, E., Mougin, C., Pontie, M., 2000, Immobilization of laccase from Trametes versicolor on a modified PVDF microfiltration membrane: characterization of the grafted support and application in removing a phenylurea pesticide in wastewater, J. Membr. Sci., 180(1), 103-113.

Le-Clech, P., Chen, V., Fane, T. A. G., 2006, Fouling in membrane bioreactors used in wastewater treatment, J. Membr. Sci., 284(1-2), 17-53.

Li, X. Y., Chu, H. P., 2003, Membrane bioreactor for the drinking water treatment of polluted surface water supplies, Water Res., 37(19), 4781-4791.

Melin, T., Jefferson, B., Bixio, D., Thoeye, C., De Wilde, W., De Koning, J., van der Graaf, J., Wintgens, T., 2006, Membrane bioreactor technology for wastewater treatment and reuse, Desalination, 187, 271-282.

Nakamura, K., Matsumoto, K., 2006, Properties of protein adsorption onto pore surface during microfiltration: effects of solution environment and membrane hydrophobicity, J. Membr. Sci., 280(1-2), 363-374.

Shin, C. H., 2009, Initial operating condition of membrane bioreactor with PVDF hollow fiber and permeate reuse, J. Clean Technology, 16(1), 39-45.

Shin, C. H., 2008, Development of optimization techniques and practical use of a MBR to reduce the size of final clarifiers, Technical report, Busan environmental corporation.

Shin, C. H., Johnson, R., 2007, Permeat characterisrics and operation condition of membrane bioreactor with the dispersing modified hollow fiber, J. Ind. Eng. Chem., 13, 40-46.

Shin, C. H., Seo, J. M., Bae, J. S., 2009, Modification of a hollow fiber membrane and its three-dimensional analysis of surface pore and internal structure for a water reclamation system, J. Ind. Eng. Chem., 15, 784-790.

Singh, N., Husson, S. M., Zdyrko, B., Luzinov, I., 2005, Surface modification of microporous PVDF membranes by ATRP, J. of Memb. Sci., 262(1-2), 81-90.

Ueda, T., Hata, K., Kikuoka, Y., Seino, O., 1997, Effects of aeration on suction pressure in a submerged membrane bioreactor, Water Res., 31, 489-494.

Visvanathan, C., Boonthanon, N., Sathasivan, A., Jegatheesan, V., 2003, The use of microfiltration membranes for seawater pre-treatment prior to reverse osmosis membranes, Desalination, 153, 133-140.

Yamamori, H., Hoshelde, A., Kobayashi, M., 1996, Hollow Fiber Membrane Module, U.S. Patent, 5480553.

Yamamoto, K., Hiasa, M., Mahmood, T., Matsuo, T., 1989, Direct solid-liquid separation using hollow fiber membrane in an activated sludge aeration tank, Water Sci. Technol., 21, 43-54.

Yamamoto, N., Kimura, K., Miyoshi, T., Watanabe, Y., 2006, Difference in membrane fouling in membrane bioreactors (MBRs) caused by membrane polymer materials, J. Membr. Sci., 280(1-2), 911-919.

Yang, W., Cicek, N., Ilg, J., 2006, State-of-the-art of membrane bioreactors: Worldwide research and commercial applications in North America, J. Membr. Sci., 270, 201-271. 